\title{
Rescuing $\mathrm{qk}^{\mathrm{v}}$ Dysmyelination by a Single Isoform of the Selective RNA-Binding Protein QKI
}

\author{
Lixia Zhao, ${ }^{1}$ Donghua Tian, ${ }^{1}$ Mingjing Xia, ${ }^{1}$ Wendy B. Macklin, ${ }^{2}$ and Yue Feng ${ }^{1}$ \\ ${ }^{1}$ Department of Pharmacology, Emory University School of Medicine, Atlanta, Georgia 30322, and ${ }^{2}$ Department of Neurology, Northwestern University, \\ Chicago, Illinois 60611
}

\begin{abstract}
Alternative splicing of the $q k I$ transcript generates multiple isoforms of the selective RNA-binding protein QKI, which play key roles in controlling the homeostasis of their mRNA targets. QKI deficiency in oligodendrocytes of homozygous quakingviable (qk $\mathrm{k}^{\mathrm{v}} / \mathrm{qk}^{\mathrm{v}}$ ) $\mathrm{mutant}$ mice results in severe hypomyelination, indicating the essential function of QKI in myelinogenesis. However, the molecular mechanisms by which QKI controls myelination remain elusive. We report here that QKI-6 is the most abundant isoform in brain and is preferentially reduced in the $\mathrm{qk}^{\mathrm{v}} / \mathrm{qk}^{\mathrm{v}}$ mutant during normal myelinogenesis. To test whether QKI-6 is the predominant isoform responsible for advancing CNS myelination, we developed transgenic mice that express Flag-QKI-6 specifically in the oligodendroglia lineage, driven by the proteolipid protein (PLP) promoter. When introduced into the $\mathrm{qk}^{\mathrm{v}} / \mathrm{qk}^{\mathrm{v}}$ mutant, the QKI- 6 transgene rescues the severe tremor and hypomyelination phenotype. Electron microscopic studies further revealed that the Flag-QKI-6 transgene is sufficient for restoring compact myelin formation with normal lamellar periodicity and thickness. Interestingly, Flag-QKI-6 preferentially associates with the mRNA encoding the myelin basic protein (MBP) and rescues MBP expression from the beginning of myelinogenesis. In contrast, Flag-QKI-6 binds the PLP mRNA with lower efficiency and has a minimal impact on PLP expression until much later, when the expression level of QKI-6 in the transgenic animal significantly exceeds what is needed for normal myelination. Together, our results demonstrate that QKI-6 is the major isoform responsible for CNS myelination, which preferentially promotes MBP expression in oligodendrocytes.
\end{abstract}

Key words: myelination; quakingviable; $\mathrm{qk}^{\mathrm{v}}$; myelin basic protein; MBP; proteolipid protein; PLP; QKI RNA-binding protein

\section{Introduction}

Quakingviable $\left(\mathrm{qk}^{\mathrm{v}}\right)$ is a spontaneous recessive mutation in mouse (Ebersole et al., 1992). Homozygous $\mathrm{qk}^{\mathrm{v}}$ mutants suffer from diminished expression of myelin structural proteins and severe hypomyelination (Sidman et al., 1964; Hogan and Greenfield, 1984; Hardy, 1998). The $\mathrm{qk}^{\mathrm{v}}$ mutation deletes an enhancer of the qkI gene (Ebersole et al., 1996) and causes diminished qkI transcription specifically in myelin-producing cells (Hardy et al., 1996; Lu et al., 2003), which is postulated as the cause for dysmyelination (Hardy, 1998; McInnes and Lauriat, 2006). Three major QKI protein isoforms, designated as QKI-5, QKI-6, and QKI-7, are expressed in glia but absent in neurons (Hardy et al., 1996; Kondo et al., 1999). These isoforms have distinct $C$ termini as a result of alternative splicing of the $3^{\prime}$ coding exons. The common $\mathrm{N}$ terminus contains a $\mathrm{KH}$ (K-homology) RNA-binding domain, followed by a tyrosine cluster that mediates Src family-protein tyrosine kinase (Src-PTK)-dependent phosphorylation, which modulates the RNA-binding activity of QKI (Zhang et al., 2003). The distinct $\mathrm{C}$ termini determine the subcellular localization of QKI isoforms. QKI-5 is mainly nuclear, whereas QKI-6 and QKI-7 are predominantly cytoplasmic (Hardy et al., 1996; Wu et al., 1999). Thus, QKI isoforms are postulated to exert differential

\footnotetext{
Received June 23, 2006; revised Sept. 17, 2006; accepted Sept. 22, 2006.

Correspondence should be addressed to Dr. Yue Feng, Department of Pharmacology, Emory University School of Medicine, 1510 Clifton Road, Atlanta, GA 30322. E-mail: yfeng@emory.edu. DOI:10.1523/JNEUROSCI.2677-06.2006

Copyright $\odot 2006$ Society for Neuroscience ～0270-6474/06/2611278-09\$15.00/0
}

influence on myelination (Hardy, 1998; Cox et al., 1999). QKI-5 is highly expressed in the embryonic and neonatal brain, but its expression gradually decreases during myelinogenesis (Hardy et al., 1996; Kondo et al., 1999). In contrast, QKI-6 and QKI-7 are vigorously upregulated during active myelination. Therefore, although QKI isoforms appear to bind mRNA ligands with similar selectivity (Larocque et al., 2002, 2005; Zhang et al., 2003), the net influence of QKI isoforms on a particular mRNA target may vary significantly at different developmental stages.

One of the mRNA ligands of QKI during myelin development in the CNS encodes the myelin basic protein (MBP). All QKI isoforms bind the MBP 3'-untranslated region (UTR) (Li et al., 2000; Zhang and Feng, 2001). QKI-6 has been shown to stabilize the MBP mRNA via the $3^{\prime}$-UTR (Zhang et al., 2003), whereas overexpression of QKI-5 in oligodendrocytes results in nuclear retention of the MBP $\mathrm{mRNA}$, thereby inhibiting MBP protein expression (Larocque et al., 2002). In the $\mathrm{qk}^{\mathrm{v}}$ mutant, all three QKI isoforms are decreased (Hardy et al., 1996; Lu et al., 2003). Thus, it is unclear which QKI isoform is functionally required for CNS myelination. Moreover, because $\mathrm{qk}^{\mathrm{v}}$ causes dysregulation of multiple myelin structural mRNAs (Campagnoni et al., 1987; Campagnoni and Macklin, 1988; Hardy, 1998), it has been unclear which of the affected mRNA(s) is a primary QKI binding target and how QKI thereby regulates myelination.

In this study, we report that expression of the QKI-6 isoform alone in the oligodendroglia lineage of the $\mathrm{qk}^{\mathrm{v}}$ mutant is sufficient to rescue the severe hypomyelination phenotype without 
altering the expression of other QKI isoforms, indicating that QKI-6 is both sufficient and necessary for CNS myelinogenesis. In addition, we provide molecular evidence that MBP mRNA is a preferential target for QKI to control CNS myelination.

\section{Materials and Methods}

Transgenic construct and production of transgenic mice. To generate the proteolipid protein (PLP)-Flag QKI-6 transgenic construct, we first inserted the Flag-QKI-6 cDNA in the pNEB vector (Fuss et al., 2000). The AscI-PacI fragment containing the Flag-QKI-6 cDNA was then subcloned downstream of the PLP promoter in the PLP-SV40-PL plasmid, which has been shown to drive reporter gene expression with similar temporal/spatial profiles compared with that of endogenous PLP (Fuss et al., 2000; Mallon et al., 2002). Transgenic mice were generated in the Emory Transgenic Mouse Core Facility. The ApaI-SacII fragment $(\sim 12$ $\mathrm{kb}$ ) containing the PLP promoter and the Flag-QKI-6 cDNA was injected into the pronuclei of fertilized oocytes that were transferred into pseudopregnant mice. Potential $F_{1}$ founders that carry the transgene were screened using a PCR-based genotyping assay by specific primers for the QKI-6 transgene and further confirmed by Southern blot analysis as described below. To introduce the transgene into the $\mathrm{qk}^{\mathrm{v}} / \mathrm{qk}^{\mathrm{v}}$ background, $\mathrm{qk}^{\mathrm{v}} / \mathrm{wt}$ mice that carry the QKI- 6 transgene were mated, and the $\mathrm{qk}^{\mathrm{v}} / \mathrm{qk}^{\mathrm{v}}$ descendants that carry the QKI-6 transgene were identified by PCR before being subjected to biochemical and morphological studies.

Southern blot and PCR-based genotyping. Genomic DNA (10 $\mu \mathrm{g})$ was digested with SalI or XhoI, electrophoresed on $0.9 \%$ agarose gels, and transferred to nylon membrane (Amersham Biosciences, Piscataway, $\mathrm{NJ}$ ). The blots were hybridized to random primed QKI-6 probes (XhoI fragment from PCQKI-6) according to the manufacturer's instruction (Amersham Biosciences). A PCR-based assay was performed routinely to identify the presence of the transgene from genomic DNA isolated from the tail with the following primers: 5'-ATATCATGCTTGCCTCTGGGGTGG-3' (forward) and 5'-GGGCTGGTGATTTAATGTTGGCGT-3' (reverse). The $\mathrm{qk}^{\mathrm{v}}$ allele was distinguished from the wt allele by primers flanking the break point, $5^{\prime}$-TCACTCATTCCTTGGTTCATGT-3' (forward) and 5'-TGGCCAACGCCTATTTTTAC-3' (reverse). The wt allele was detected using primers located within the $\mathrm{qk}^{\mathrm{v}}$ deletion, 5'-GAAAGGATTGGGGGTAGAGC-3' (forward) and $5^{\prime}$ GCAGGGGGAGAAAGAAAATC-3' (reverse).

Western blot and immunohistochemistry. Mouse tissue was homogenized in $50 \mathrm{~mm}$ Tris- $\mathrm{HCl}, \mathrm{pH} 7.5,150 \mathrm{~mm} \mathrm{NaCl}$, and 0.5\% Triton X-100 in the presence of protease inhibitor mixtures (Roche, Indianapolis, IN). The protein concentration of each sample was estimated by Bradford assay following manufacturer's protocol (Bio-Rad, Hercules, CA) before being subjected to SDS-PAGE with equal loading for each sample. The monoclonal rat anti-MBP antibody (1:1000) was purchased from Chemicon (Temecula, CA), anti-Flag M2 (1:3000) was purchased from Sigma (St. Louis, MO), and anti-eIF5 $\alpha$ (1:5000) was purchased from Santa Cruz (Santa Cruz, CA).

For immunohistochemistry, mice were deeply anesthetized with sodium pentobarbital $(60 \mathrm{mg} / \mathrm{kg})$ and perfused transcardially through the ascending aorta with warm heparinized saline followed by ice-cold $4 \%$ paraformaldehyde in $0.01 \mathrm{M}$ PBS, pH 7.4. Brains were quickly removed and cryoprotected in $20 \%$ sucrose in $0.1 \mathrm{M} \mathrm{PBS}$ at $4^{\circ} \mathrm{C}$ overnight. Coronal and sagittal sections $(40 \mu \mathrm{m})$ were collected onto gelatin-pretreated slides using Cryostat (Leica, Nussloch, Germany). The sections were incubated with 0.1 M PBS containing $10 \%$ goat or donkey serum, $2 \%$ bovine serum protein A (BSA), $0.05 \%$ Triton X-100, and $0.01 \%$ Tween 20 for $2 \mathrm{~h}$, followed by incubation with primary antibodies in PBS containing $1 \%$ BSA for $2 \mathrm{~h}$. The following primary antibodies were used: mouse anti-Flag (1:1000; Sigma), rabbit anti-Flag (1:1000; Sigma), rabbit antiGFAP (1:1000; Sigma), mouse anti-neuron-specific enolase (NSE) (1: 200; Sigma), rat anti-MBP (1:80; Chemicon), rabbit anti-NG2 (1:200; Chemicon), mouse anti-APC (adenomatous polyposis coli; clone CC1) (1:50; Chemicon), and mouse anti-2' $3^{\prime}$-cyclic nucleotide $3^{\prime}$ phosphodiesterase (CNP) (1:100; Chemicon). After washing, corresponding secondary antibodies conjugated with either FITC or Texas Red were incubated with the slides for $2 \mathrm{~h}$ at room temperature. Fluoro-
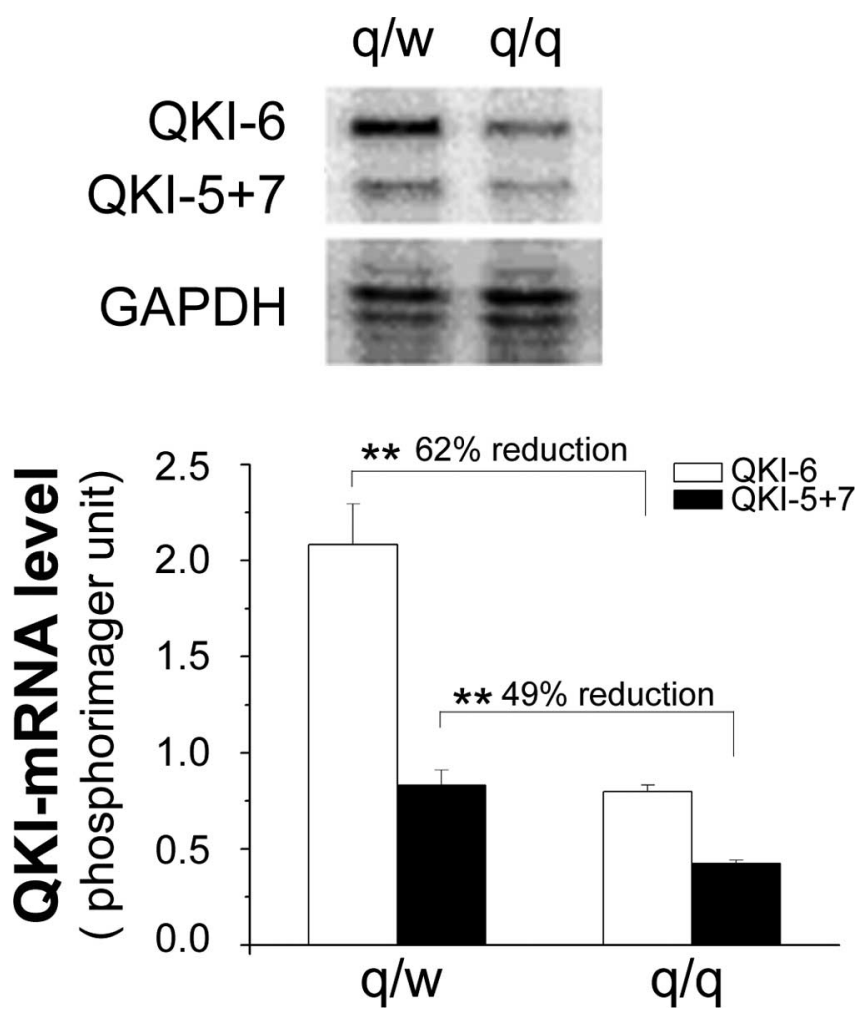

Figure 1. Preferential reduction of QKI- 6 in the $\mathrm{qk}^{\mathrm{v}}$ corpus callosum. Three micrograms of total RNA from corpus callosum was used for RPA analysis. The top panel shows a representative phosphorimage of the RPA gel. GAPDH was used as a loading control. The bottom panel displays Phosphorlmager reading of QKI mRNA isoforms normalized to that of GAPDH. The percentage of reduction of QKI-6 and QKI-5+7 in $q \mathrm{k}^{\mathrm{v}} / \mathrm{qk}^{\mathrm{v}}$ mice $(\mathrm{q} / \mathrm{q})$ compared with the $\mathrm{qk} / \mathrm{wt}$ control $(\mathrm{q} / \mathrm{w})$ is indicated. SE is indicated for each group $(n=5) .{ }^{* *} p<0.01$ based on standard $t$ test.

Myelin Red staining (1:300) was performed according to manufacturer's protocol (Invitrogen, Carlsbad, CA). Fluorescent signals were detected using the Zeiss (Oberkochen, Germany) LSM 510 confocal microscopic imaging system or an inverted fluorescence microscope (IX51; Olympus, Tokyo, Japan) equipped with a RETIGA digital camera.

$R N A$ preparation and RNase protection assay. RNA was extracted from various brain regions using Trizol reagent according to manufacturer's protocol (Invitrogen). The quantity of RNA was determined by $\mathrm{OD}_{260}$ reading and further confirmed on ethidium bromide-stained agarose gel after electrophoresis. The RNase protection assay (RPA) probes for MBP, QKI-6, and glyceraldehyde phosphate dehydrogenase (GAPDH) were generated as described previously (Li et al., 2000; Lu et al., 2003). For generating the RPA probe of PLP, a cDNA fragment was amplified by RT-PCR with primers of 5'-GCAAGGGCCTGAGCGCAACG-3' (forward) and 5' -GCAGATGGACAGAAGGTTGGAG-3' (reverse) using total mouse brain RNA. This PLP cDNA fragment was cloned into Bluescript II KS (Stratagene, La Jolla, CA), and proved to be $100 \%$ identical to published sequence. Antisense riboprobes were generated by in vitro transcription in the presence of $\left[{ }^{32} \mathrm{P}\right] \mathrm{UTP}$ (Amersham Biosciences) using linearized plasmids as DNA template. Each probe $\left(5 \times 10^{5} \mathrm{cpm}\right)$ was hybridized to RNA samples as indicated in the corresponding figure legends followed by RPA analysis using previously published procedures (Li et al., 2000).

Electron microscopic analysis. Mice were anesthetized with equithesin and perfused with $2.5 \%$ glutaraldehyde in $0.1 \mathrm{~m}$ phosphate buffer, $\mathrm{pH} 7.4$. The brain and optic nerves were removed and fixed overnight at $4^{\circ} \mathrm{C}$ in the above fixative. Tissue was vibratomed into $0.3 \mathrm{~mm}$ sections containing the area of interest. The sections were washed in $0.1 \mathrm{M}$ cocadylate buffer, $\mathrm{pH} 7.2$, postfixed in $1 \%$ osmium, dehydrated in graded alcohol series, infiltrated with Epon resin, and eventually embedded in fresh resin. Sections of selected blocks were cut, mounted on grids, counter- 
stained with uranyl acetate and lead citrate, and examined with a Hitachi (Tokyo, Japan) H-7500 Electron Microscope.

In vitro RNA-binding and immunoprecipitation of QKI-RNA complexes. [ $\left.{ }^{35} \mathrm{~S}\right]$ Methioninelabeled QKI was generated as described previously (Li et al., 2000). Biotinylated transcripts were derived from in vitro synthesis using T7 polymerase and incubated with ${ }^{35} \mathrm{~S}-\mathrm{QKI}$. The RNA-bound ${ }^{35} \mathrm{~S}-\mathrm{QKI}$ was captured by streptavidin-conjugated Dynal beads (Li et al., 2000) followed by SDS-PAGE. Brainstem and cerebellum were dissected from mice at postnatal day 10 (P10), homogenized, and lysed in an ice-cold buffer including $50 \mathrm{~mm}$ Tris, $\mathrm{pH} 7.5,150 \mathrm{~mm} \mathrm{NaCl}, 10 \mathrm{~mm}$ EDTA, $0.5 \%$ Triton X-100, protease inhibitor, and RNase inhibitors. The postnuclear supernatant was precleared with IgG-conjugated protein A-Sepharose and Sepharose $4 \mathrm{~B}$, incubated with anti-Flag M2 beads (Sigma) for $2 \mathrm{~h}$ at $4^{\circ} \mathrm{C}$, extensively washed before being eluted with $0.2 \mathrm{mg} / \mathrm{ml}$ Flag peptide for $2 \mathrm{~h}$ at $4^{\circ} \mathrm{C}$, and then subjected to RNA extraction using Trizol. Real-time quantitative RT-PCR (qRT-PCR) was performed with DyNAmo SYBR Green qPCR kits (New England Biolabs, Beverly, MA). The following sets of primers were used: for MBP, 5'-CTCCCTGCCCCAGAAGTCGC-3' (forward) and 5'-CTCTTCCTCCCCAGCTAAATCTGC-3' (reverse); for PLP, 5'-CTTTGGAGCGGGTGTGTCATTGTT-3' (forward) and 5' -ACACCAGGAGCCATACAACAGTCA-3' (reverse); for GAPDH, 5' CACAGTCAAGGCTGAGAATGGGAAG-3' (forward) and 5'-GTGGTTCACACCCATCACAAACATG-3' (reverse).

\section{Results}

Generation of transgenic mice that express Flag-QKI-6 in the oligodendrocyte lineage

Our previous work showed that QKI-6 is the most abundant QKI isoform during normal brain development ( $\mathrm{Lu}$ et al., 2003). To determine the quantitative reduction of the different QKI mRNA isoforms caused by the $\mathrm{qk}^{\mathrm{v}}$ mutation, we performed RPA using total RNA derived from dissected corpus callosum that is mostly enriched of oligodendrocytes in the brain. As shown in Figure 1, QKI-6 mRNA was more severely reduced than the other QKI mRNA isoforms in the $\mathrm{qk}^{\mathrm{v}} / \mathrm{qk}^{\mathrm{v}}$ corpus callosum compared with that in the nonphenotypic $\mathrm{qk}^{\mathrm{v}} / \mathrm{wt}$ littermate. This led us to hypothesize that QKI-6 is the crucial isoform that governs normal myelinogenesis. To test this hypothesis, we developed a transgenic construct in which the FlagQKI-6 cDNA was engineered downstream of the PLP promoter-enhancer module (Fig. 2A) that contains all the functional entities required for spatial and temporal expression in oligodendrocyte during CNS development (Fuss et al., 2000; Mal-

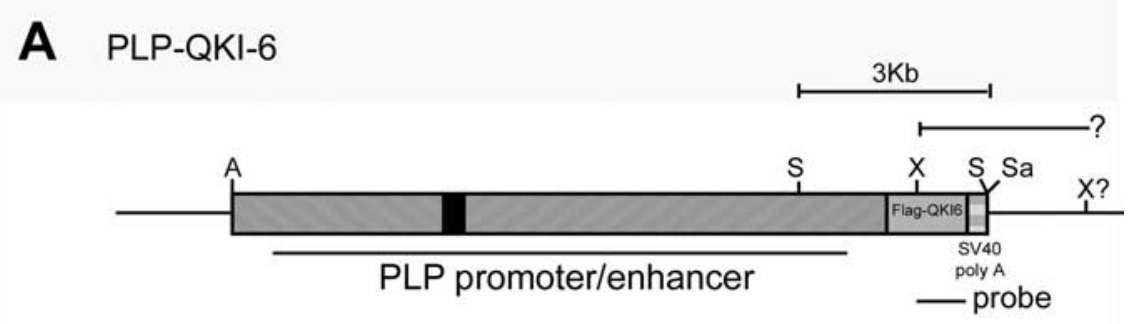

B
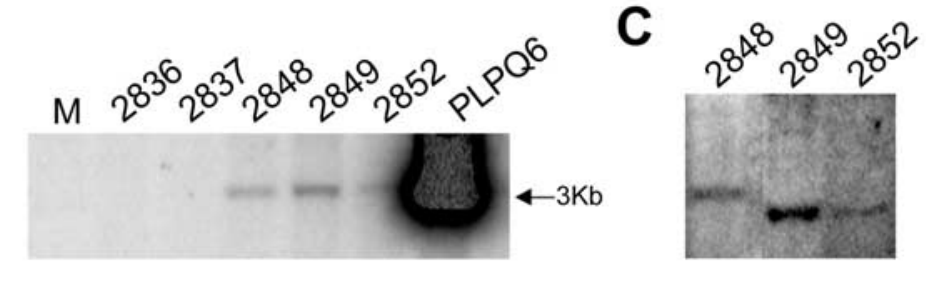

D

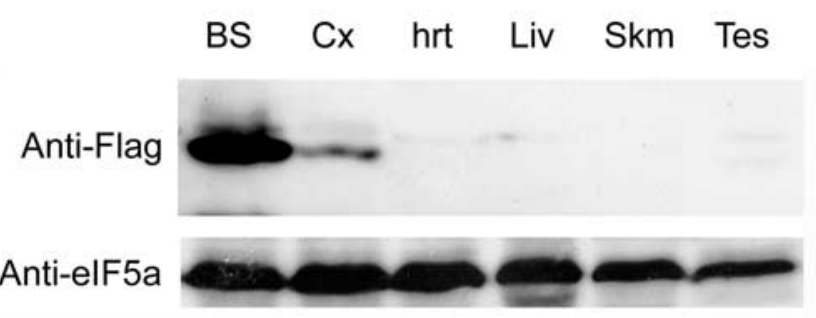

E
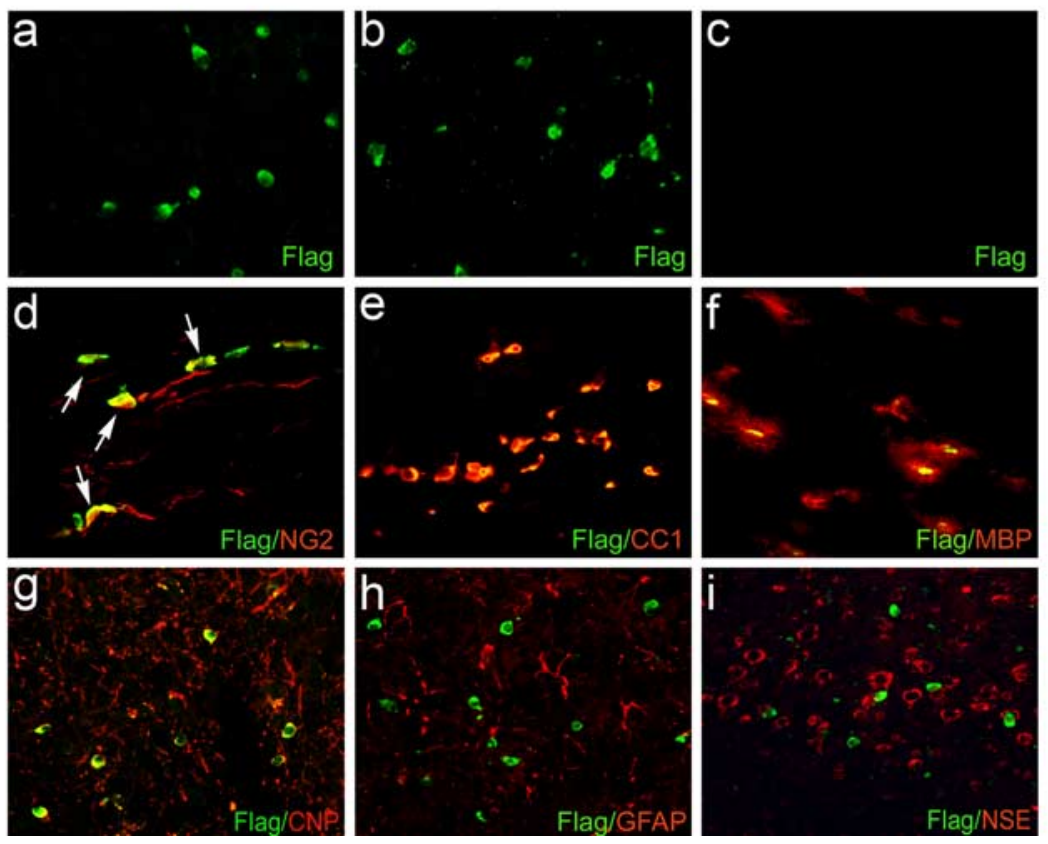

Figure 2. Generation of PLP-QKI-6 transgenic mice. $A$, The PLP-QKI-6 transgenic construct. The Apal (A)-Sacll (Sa) fragment containing the PLP promoter/enhancer and the Flag-QKI- 6 cDNA was used for oocyte injection. The $0.8 \mathrm{~kb}$ Xhol (X) fragment of Flag-QKI- 6 was used as a probe for genomic Southern. Genomic DNA was either digested by Sall (S) or Xhol for genomic Southern analysis. $\boldsymbol{B}, \boldsymbol{C}$, Genomic Southern blot analysis. Ten micrograms of genomic DNA were digested with Sall ( $\boldsymbol{B}$ ), which generates a 3 $\mathrm{kb}$ fragment within the transgenic construct. Xhol digestion detects fragments with distinct sizes in the three founder lines (C). $\boldsymbol{D}$, Tissue specific expression of Flag- $0 \mathrm{KL}-6$ transgene. Fifteen micrograms of total protein from different tissues, including brainstem (BS), cortex (Cx), heart (hrt), liver (Liv), skeletal muscle (Skm), and testis (Tes), of a 1-month-old transgenic mouse were analyzed. The blot was reprobed with the housekeeping protein elF5a to provide a loading control. $\boldsymbol{E}$, Oligodendrocyte specific expression of the Flag-QKI-6 transgene. Flag-QKI-6 (green) was predominantly localized in the cytoplasm of the transgenic mice $(\boldsymbol{a}, \mathrm{P5}$ 
A

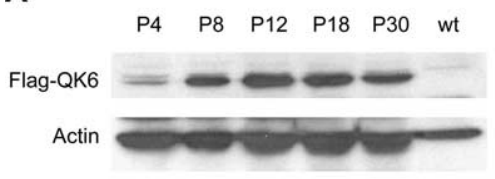

B

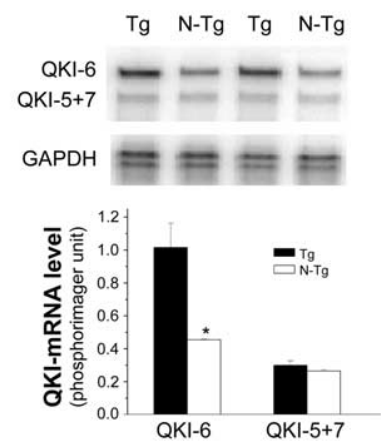

C

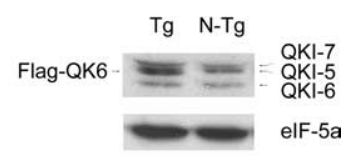

D

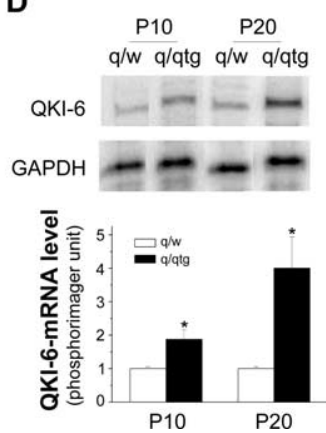

A

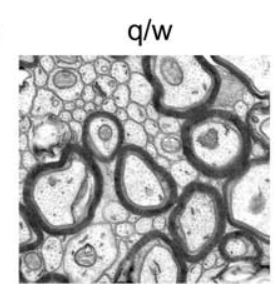

B
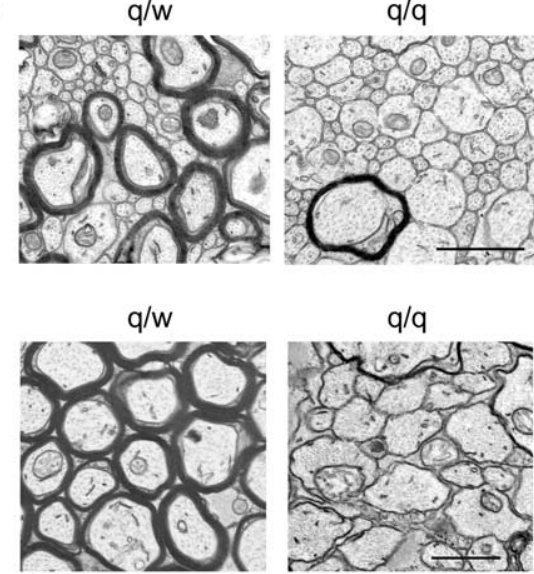

$\mathrm{q} / \mathrm{q}$

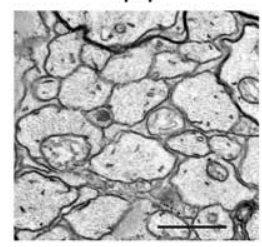

q/qtg

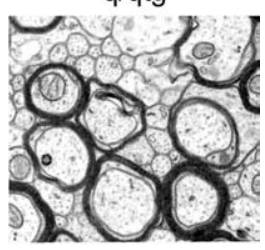

q/qtg

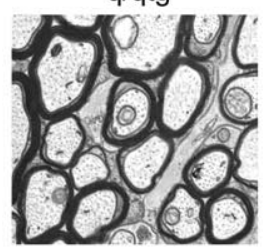

C
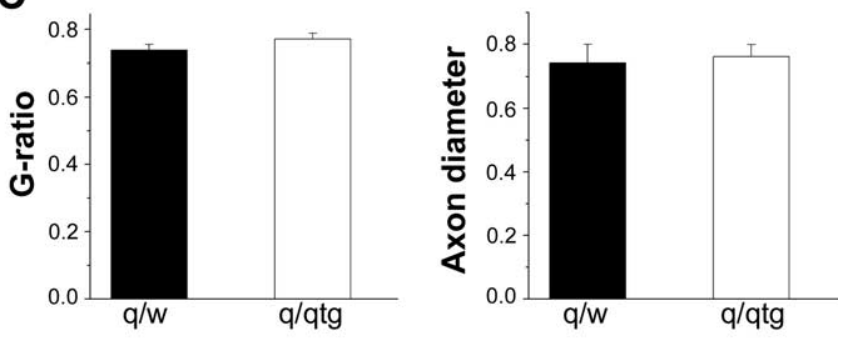

D
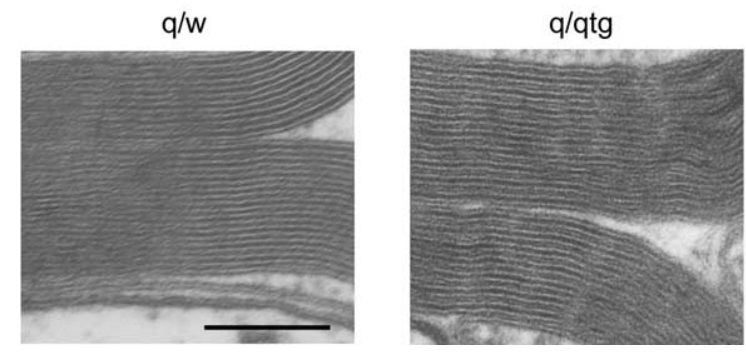

Table 1. QKI-6 transgene rescues "quaking" phenotype of quakingviable mutant

\begin{tabular}{|c|c|c|c|c|}
\hline & $\mathrm{qk}^{2} / \mathrm{wt}^{2}$ & wt & $q^{2} / q k^{2}$ & Total \\
\hline \multicolumn{5}{|l|}{2848} \\
\hline $\mathrm{Tg}+$ & 94 & 32 & $\begin{array}{l}34 \\
0 \% \text { tremor }\end{array}$ & 160 \\
\hline $\mathrm{Tg}-$ & 40 & 17 & $\begin{array}{l}5 \\
100 \% \text { tremor }\end{array}$ & 72 \\
\hline Total & 134 & 49 & 49 & 232 \\
\hline \multicolumn{5}{|l|}{2852} \\
\hline $\mathrm{Tg}+$ & 14 & 8 & $\begin{array}{l}17 \\
0 \% \text { tremor }\end{array}$ & 39 \\
\hline $\mathrm{Tg}-$ & 5 & 5 & $\begin{array}{l}6 \\
100 \% \text { tremor }\end{array}$ & 15 \\
\hline Total & 19 & 13 & 22 & 54 \\
\hline
\end{tabular}

Rescuing the tremor phenotype in the $q \mathrm{k} / \mathrm{qk}$ mutant by the Flag- $0 \mathrm{KI}-6$ transgene. The number of transgenic $(\mathrm{Tg}+)$ and nontransgenic $(\mathrm{Tg}-)$ in the indicated genotypes from the 2848 and the 2852 founders are indicated.
Figure 4. The QKI-6 transgene restores compact myelin formation in the $\mathrm{qk}^{\mathrm{v}}$ mutant. $\boldsymbol{A}, \boldsymbol{B}$, Electron micrograph (EM) of cross sections showing the myelinated axons in the corpus callosum $(\boldsymbol{A})$ and the optic nerve $(\boldsymbol{B})$ of the control $(q / w)$, homozygous $q k^{v}$ mutant $(q / q)$, and transgenic $q \mathrm{k}^{\mathrm{v}}$ mice (q/qtg). C, Average $\mathrm{g}$ ratio and axon diameter of optic nerve derived from the $q / w$ and $q / q t g$ littermates. More than 100 myelinated axons were analyzed in each mouse, and three mice were analyzed in each group. Error bars indicate SE. D, High-resolution EM revealed normal periodicity of major dense line and intraperiod line in $q / w$ and $q / q$ tg littermates. Scale bar, $1 \mu \mathrm{m}$.

lon et al., 2002). Three founders $(2848,2849$, and 2852) carried the QKI-6 transgene and were able to pass the transgene into germ cells based on genomic Southern analysis (Fig. $2 B, C$ ) and PCR genotyping (described in Materials and Methods).

Immunoblot analysis revealed that Flag-QKI-6 was predominantly expressed in the brain, with very weak expression in the testes, and no detectable expression in any other tissues examined including heart, liver, and skeletal muscle (Fig. 2D). Noticeably, much higher levels of Flag-QKI-6 were detected in the brainstem, which contains more oligodendrocytes than cerebral cortex (Fig. $2 D)$. This pattern of tissue specificity was observed in all three transgenic founder lines (data not shown). To further define the cell type specificity of the Flag-QKI-6 transgene, we performed immunohistochemistry in which brain sections were double-stained using anti-Flag antibody corpus callosum; $\boldsymbol{b}$, P17 cortex), but not in the nontransgenic littermate (c, P17 cortex). Expression of Flag-OKI-6 (green) specifically in the oligodendrocyte lineage is indicated by double immunofluorescence labeling. Specific markers (red) indicate various neural cell types at developmental stages, including the oligodendroglia lineage markers NG2 (d arrows, P5 corpus callosum), CC1 ( $\boldsymbol{e}$, P5 corpus callosum), MBP ( $\boldsymbol{f}$, P5 corpus callosum), CNP ( $\boldsymbol{g}$, P17 striatum), the astrocyte marker GFAP ( $\boldsymbol{h}$, P17 cortex), and the neuronal marker NSE (i, P17 cortex). 
and antibodies that mark cells in various developmental stages of the oligodendroglial lineage, neurons and astrocytes. As shown in Figure 2 E, Flag staining (green) was detected specifically in the cytoplasm of cells in transgenic animals (Fig. $2 E a, b$ ), but not in the nontransgenic littermate control (Fig. $2 E c$ ). In addition, Flag staining was localized in oligodendroglia progenitor cells $(\mathrm{NG} 2+)$ (Fig. $2 E d$ ), mature oligodendrocytes $(\mathrm{CC} 1+)$ (Fig. 2Ee), and myelinating oligodendrocytes (MBP+ and $\mathrm{CNP}+$ ) (Fig. $2 E f, g$, respectively). In contrast, no Flag staining was detected in astrocytes (GFAP+) (Fig. 2 Eh) or neurons $(\mathrm{NSE}+)$ (Fig. 2Ei). Therefore, the expression of Flag-QKI-6 is restricted to the oligodendroglial lineage.

The developmental expression profile of Flag-QKI-6 in the brain recapitulated that of PLP (Fig. 3A). Flag-QKI-6 was at low levels in neonates (P4) and gradually increased to reach a peak between P12 and $\mathrm{P} 18$, along with the most active myelinogenesis. The expression level of the transgene started to decline thereafter. This profile is also similar to that of the endogenous QKI-6 during normal brain development (Zhang et al., 2003). Quantitative RPA experiments revealed that expression
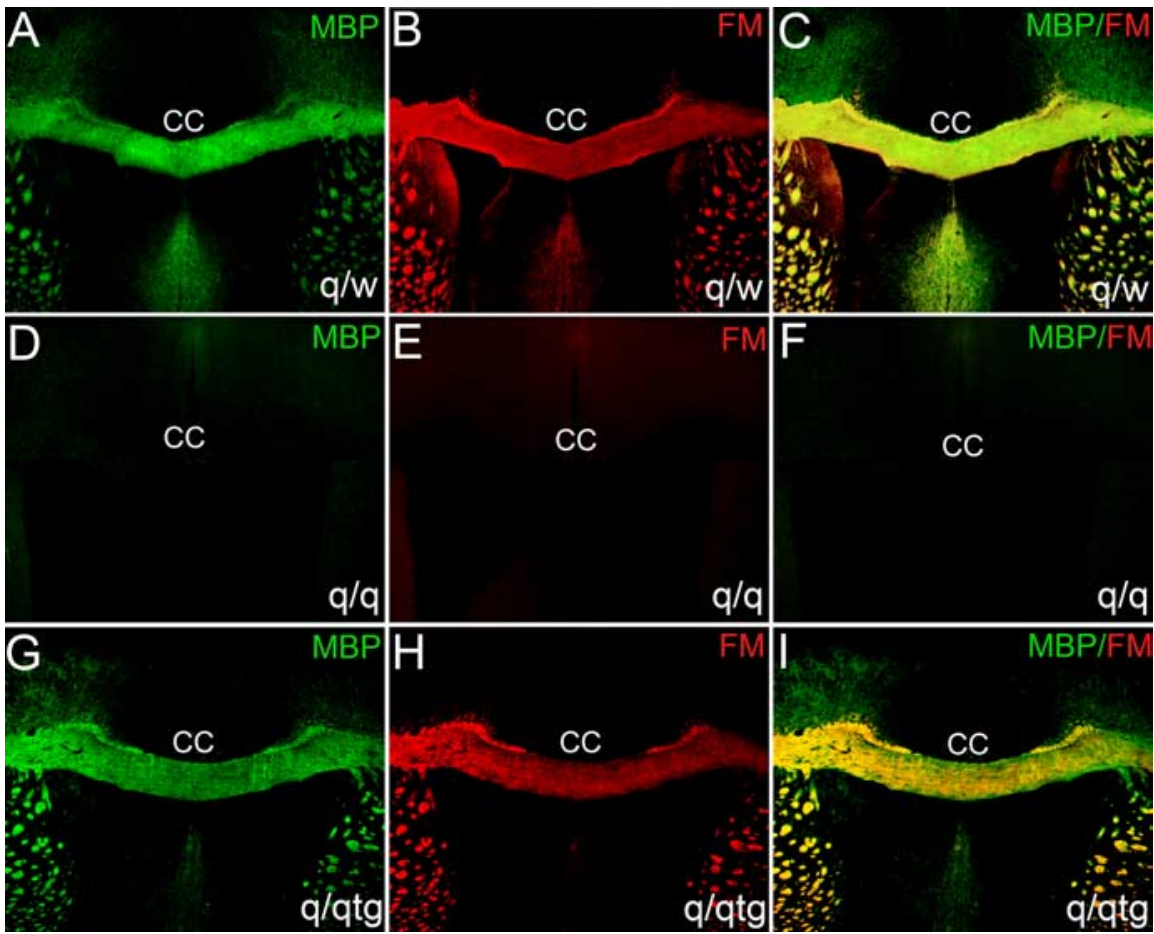

Figure 5. FluoroMyelin (FM) staining and MBP immunostaining in the corpus callosum (CC) of $q / w$ (top), $q / q$ (middle), and q/qtg (bottom) littermates. Cross sections were double-stained with anti-MBP antibody (green; $\boldsymbol{A}, \boldsymbol{D}, \boldsymbol{G}$ ) and FluoroMyelin (red; $\boldsymbol{B}$, $\boldsymbol{E}, \boldsymbol{H}$ ). The merged images indicate colocalization of FM and MBP (yellow; $\boldsymbol{C}, \boldsymbol{I}$ ). Negligible MBP and FM staining were detected in the $\mathrm{q} / \mathrm{q}$ mice, whereas q/qtg mice display normal staining intensity. from one copy of the transgene in wild-type young adult caused an approximately twofold increase of QKI-6 mRNA compared with that in nontransgenic littermates, without altering the levels of other QKI mRNA isoforms (Fig. 3B). Similarly, expression of Flag-QKI-6 did not seem to affect the level of endogenous QKI protein isoforms (Fig. 3C). When introduced into the $\mathrm{qk}^{\mathrm{v}} / \mathrm{qk}^{\mathrm{v}}$ mutant, the transgenic $\mathrm{qk}^{\mathrm{v}}$ mice (q/qtg) expressed moderately higher levels of QKI-6 mRNA than that in the nonphenotypic $\mathrm{qk}^{\mathrm{v}} /$ wt control at P10 (Fig. 3D). At the peak of myelination (P20), the level of QKI-6 mRNA in the $\mathrm{qk}^{\mathrm{v}} / \mathrm{qk}^{\mathrm{v}} \mathrm{tg}$ mice was approximately fourfold of that in $\mathrm{qk}^{\mathrm{v}} / \mathrm{wt}$ littermates (Fig. 3D). Thus, from the early stages of myelin development, significant amounts of QKI-6 were present in the $\mathrm{qk}^{\mathrm{v}} / \mathrm{qk}^{\mathrm{v}}$ tg mice, providing an excellent test regarding whether QKI-6 is functionally required for normal myelinogenesis.

\section{QKI-6 alone can rescue the $\mathrm{qk}^{\mathrm{v}}$ hypomyelination phenotype} Among the three QKI-6 transgenic founder lines, we were able to introduce the transgene from the 2848 and the 2852 founders into the $\mathrm{qk}^{\mathrm{v}} / \mathrm{qk}^{\mathrm{v}}$ background. The transgene in the 2849 founder showed $100 \%$ segregation from the $\mathrm{qk}^{\mathrm{v}}$ allele, suggesting that both the transgene and $\mathrm{qk}^{\mathrm{v}}$ are located on chromosome 17 in this founder line, and thus cannot be used in this rescuing experiment. All of the nontransgenic $\mathrm{qk}^{\mathrm{v}} / \mathrm{qk}^{\mathrm{v}}$ littermates suffer from vigorous tremors starting from postnatal day 11 and convulsive tonic/clonic seizures in adults. In contrast, none of the $\mathrm{qk}^{\mathrm{v}} / \mathrm{qk}^{\mathrm{v}} \mathrm{tg}$ mice analyzed ( 34 from the 2848 line and 17 from the 2852 line) (Table 1) showed the tremor phenotype in young mice or tonic/ clonic seizures in adults, demonstrating that the QKI-6 transgene can completely rescue the tremor phenotype.

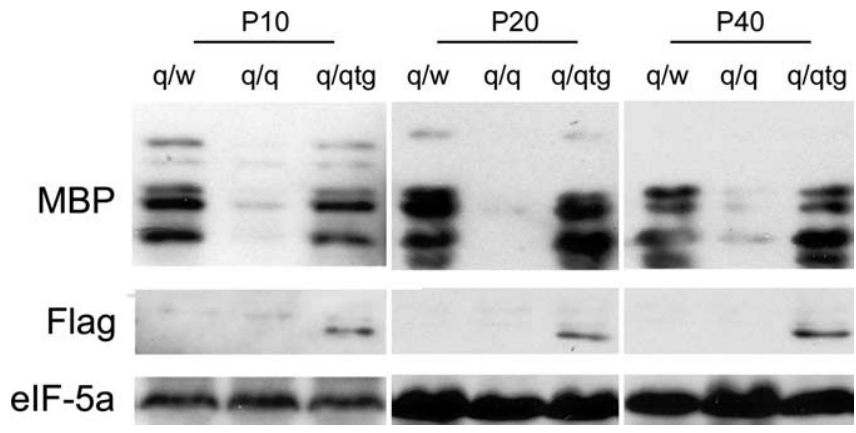

Figure 6. Flag-QKI-6 rescues MBP protein expression caused by the $\mathrm{qk}^{\mathrm{V}}$ mutation. Fifteen micrograms of total protein isolated from the cerebellum of $q / w, q / q$, and $q / q \operatorname{tg}$ mice at P10, P20, and P40 were analyzed by SDS-PAGE immunoblot for MBP expression. The anti-Flag antibody was used to confirm transgene expression; elF5a was used as a loading control.

We next tested whether the QKI-6 transgene can rescue the defects in myelination caused by $\mathrm{qk}^{\mathrm{v}}$. Electron microscopy analysis revealed that $<5 \%$ axons were myelinated in the $\mathrm{qk}^{\mathrm{v}} / \mathrm{qk}^{\mathrm{v}}$ mutant (Fig. 4A). The few myelinated axons contained reduced lamellae that failed to form compact myelin. This is consistent with previous biochemical studies indicating that the $\mathrm{qk}^{\mathrm{v}} / \mathrm{qk}^{\mathrm{v}}$ mutant produces only $5-10 \%$ of the myelin in normal animals (Singh et al., 1971; Hogan and Greenfield, 1984). In contrast, the $\mathrm{qk}^{\mathrm{v}} / \mathrm{wt}$ littermates formed compact myelin on $>80 \%$ of axons in the corpus callosum and optic nerve (Fig. $4 A, B$ ). In the $\mathrm{qk}^{\mathrm{v}} / \mathrm{qk}^{\mathrm{v}} \mathrm{tg}$ mice, robust myelination occurred in both the corpus callosum and the optic nerve (Fig. 4A,B). The numbers of myelinated axons and the average axon diameter were comparable with that in the $\mathrm{qk}^{\mathrm{v}} / \mathrm{wt}$ control (Fig. 4C). No significant difference was observed in the average $g$ ratio (axon diameter/axon diameter + myelin thickness) derived from myelinated optic nerve in $\mathrm{qk}^{\mathrm{v}}$ / 
A
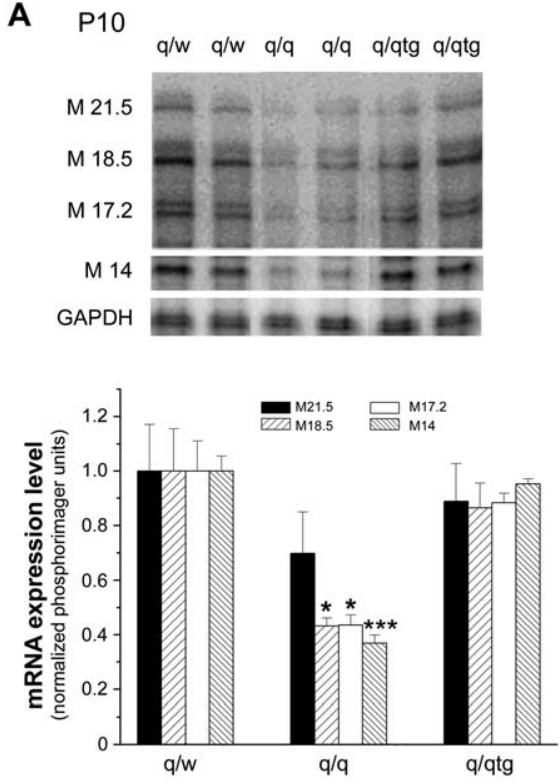

C
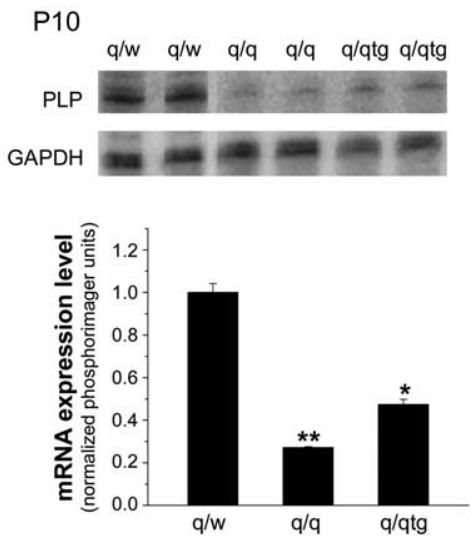

B
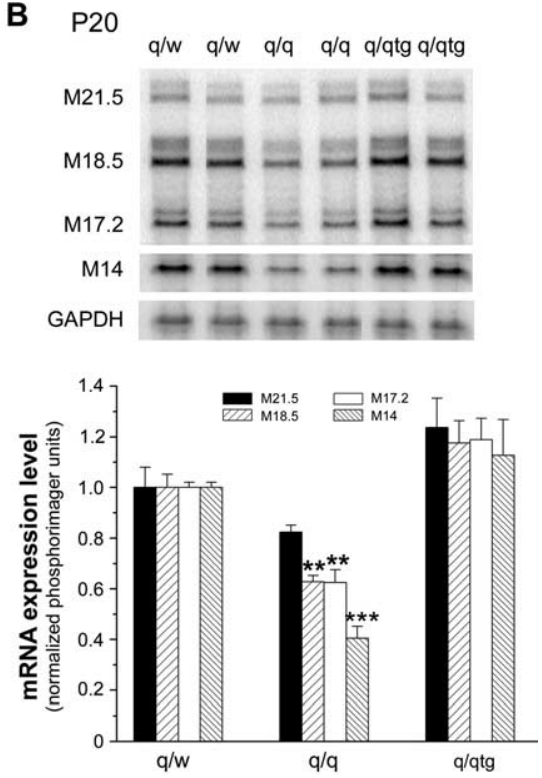

D
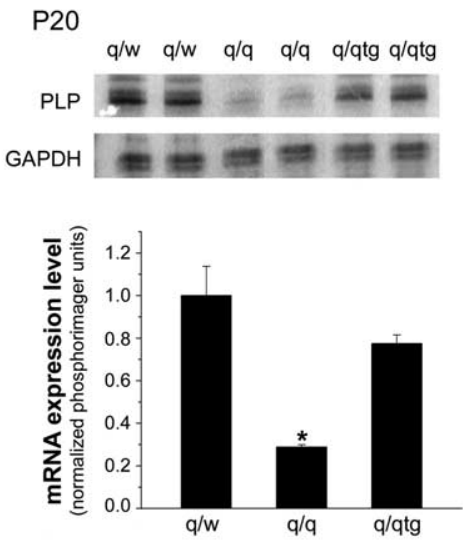

Figure 7. The influence of the QKI-6 transgene on MBP and PLP mRNA levels in the $q / q$ tg mice based on RPA. Three micrograms of RNA isolated from cerebellum was used for each RPA reaction. $A, B, M B P$ mRNA was restored to normal level as early as $P 10(A)$ and maintained at P20 (B). C, D , The QKI-6 transgene does not rescue PLP mRNA expression at P10 (C) until late stages of myelination at P20 (D). For each experiment, the top panel shows a representative phosphorimage of the RPA gel. GAPDH was used as a loading control. The Phosphorlmager reading of each MBP mRNA isoform and the PLP mRNA was normalized to that of the GAPDH mRNA and graphically displayed in the corresponding bottom panel. SE for each group is indicated $(n=3){ }^{*} p<0.05$; ${ }^{* *} p<0.01 ;{ }^{* * *} p<0.001$, when comparing data with that of $\mathrm{q} / \mathrm{w}$ controls by one-way ANOVA.

$\mathrm{qk}^{\mathrm{v}} \mathrm{tg}$ mice compared with that in the $\mathrm{qk}^{\mathrm{v}} / \mathrm{wt}$ controls. Furthermore, high magnification images of the optic nerve in $\mathrm{qk}^{\mathrm{v}} / \mathrm{qk}^{\mathrm{v}} \mathrm{tg}$ mice revealed normal lamellar periodicity with prominent major dense line and intraperiod line, comparable with that in the $\mathrm{qk}^{\mathrm{v}} / \mathrm{wt}$ controls (Fig. 4D).

To evaluate myelination in broader CNS regions, we also performed fluorescence staining using FluoroMyelin, a chemical probe that preferentially stains myelinated tracts over oligodendrocyte soma and processes. As shown in Figure 5, similar intensity of FluoroMyelin stain was observed in the corpus callosum and the cerebellum white matter (data not shown) in the $\mathrm{qk}^{\mathrm{v}}$ / $\mathrm{qk}^{\mathrm{v}} \mathrm{tg}$ mice compared with that in the $\mathrm{qk}^{\mathrm{v}} / \mathrm{wt}$ littermates, whereas negligible FluoroMyelin signals were detected in the $\mathrm{qk}^{\mathrm{v}} / \mathrm{qk}^{\mathrm{v}}$ mice. This is further confirmed by the comparable immunostaining intensity of MBP, a major component in compact myelin essential for CNS myelinogenesis (Privat et al., 1979; Readhead et al., 1987), in the aforementioned white matter areas that are heavily myelinated (Fig. 5). Together, the above results indicate that the QKI-6 transgene alone is sufficient for rescuing the hypomyelination phenotype caused by the $\mathrm{qk}^{\mathrm{v}}$ mutation.

\section{QKI preferentially binds the MBP mRNA and restores MBP expression}

The $\mathrm{qk}^{\mathrm{v}}$ mutation causes diminished expression of several myelin structural proteins, among which MBP and PLP are the most severely affected (Jacque et al., 1983; Sorg et al., 1986, 1987). Because MBP mRNA is a known target of QKI (Li et al., 2000; Larocque et al., 2002; Zhang et al., 2003), we first tested whether the QKI-6 transgene could rescue the defect in MBP expression caused by the $\mathrm{qk}^{\mathrm{v}}$ mutation. As shown in Figure 6, there was a severe reduction of the MBP protein in the $\mathrm{qk}^{\mathrm{v}} / \mathrm{qk}^{\mathrm{v}}$ mice at all ages examined. Remarkably, a single allele of the QKI-6 transgene was sufficient to restore MBP protein expression to normal in the $\mathrm{qk}^{\mathrm{v}} / \mathrm{qk}^{\mathrm{v}}$ mutant at an early stage of myelinogenesis (P10). The normal level of MBP expression was maintained throughout later development in the $\mathrm{qk}^{\mathrm{v}} / \mathrm{qk}^{\mathrm{v}}$ tg mice.

To test whether the QKI-6 transgene rescues $\mathrm{MBP}$ expression by increasing the level of MBP mRNA, we quantified the MBP mRNA splicing isoforms in $\mathrm{qk}^{\mathrm{v}} / \mathrm{qk}^{\mathrm{v}}$, $\mathrm{qk}^{\mathrm{v}} / \mathrm{wt}$, and $\mathrm{qk}^{\mathrm{v}} / \mathrm{qk}^{\mathrm{v}} \mathrm{tg}$ littermates. As shown in Figure 7, $A$ and $B$, all MBP transcripts were reduced in the $\mathrm{qk}^{\mathrm{v}} / \mathrm{qk}^{\mathrm{v}}$ mice at P10 (early myelination) and P20 (peak of myelination). The QKI-6 transgene restored MBP mRNA expression to normal levels as early as P10 (Fig. 7A). Consistent with previous reports (Campagnoni and Macklin, 1988), PLP mRNA was also affected in $\mathrm{qk}^{\mathrm{v}} / \mathrm{qk}^{\mathrm{v}}$ mutant (Fig. $7 C, D$ ). However, in contrast to the MBP mRNA, the QKI-6 transgene did not rescue PLP expression at $\mathrm{P} 10$, suggesting that the MBP mRNA is a preferential target for QKI. The PLP mRNA reached normal levels by P20 (Fig. 7D) when the QKI-6 transgene was significantly overexpressed (Fig. 3D).

We next studied whether the differential influence of QKI-6 on MBP and PLP expression was attributable to a differential ability of QKI to bind to these mRNAs. We performed in vitro RNA-binding analysis and found that the MBP mRNA binds QKI strongly in a MBP 3'-UTR-dependent manner, whereas PLP and CNP mRNAs only interact with QKI weakly (Fig. 8A). Consistent with the in vitro study, quantification of MBP and PLP mRNA in immunoprecipitated Flag-QKI-6 complexes derived from the transgenic mouse brain also demonstrated preferential association of Flag-QKI-6 with the MBP mRNA in vivo (Fig. $8 B$ ). These results support our conclusion that QKI-6 preferentially binds and enhances MBP mRNA expression during CNS myelinogenesis, and suggest that the QKI-MBP mRNA interaction is the major mechanism by which QKI-6 regulates myelinogenesis. 

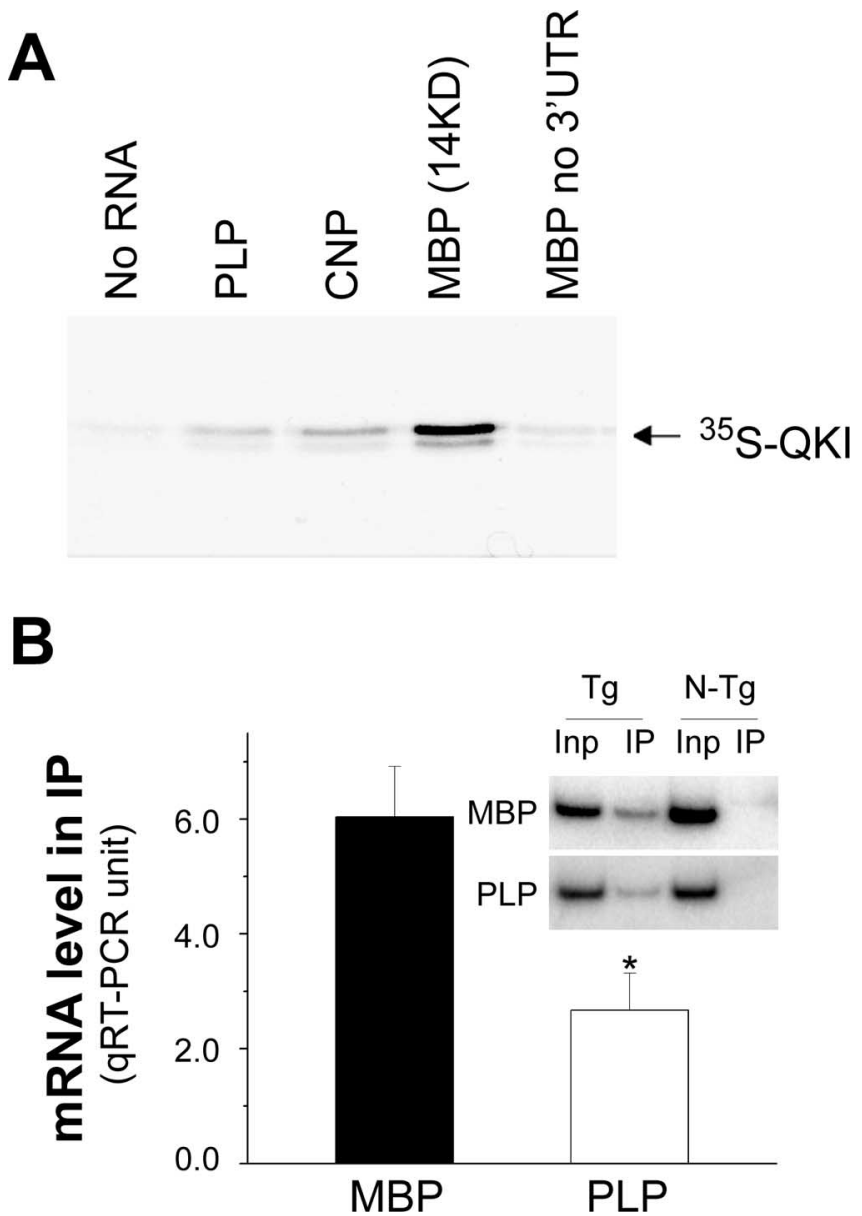

Figure 8. QKI preferentially binds the MBP mRNA over the PLP mRNA. A, Selective interaction of the MBP $m R N A$ with QKI in vitro. Full-length CDNA constructs of MBP (the $14 \mathrm{kDa}$ isoform with and without the $3^{\prime}$-UTR), PLP, and (NP were in vitro transcribed in the presence of biotinUTP and incubated individually with ${ }^{35} \mathrm{~S}-\mathrm{QKI}$ derived from in vitro translation. The biotinlabeled RNAs were captured by streptavidin-conjugated magnetic beads, and the cocaptured ${ }^{35} \mathrm{~S}$-QKI was visualized on SDS-PAGE by a Phosphorlmager. The RNA used in each reaction is depicted on top of the corresponding lanes. $\boldsymbol{B}$, The MBP $\mathrm{mRNA}$ is preferentially associated with Flag- $0 \mathrm{KL}-6$ in the transgenic mice. Cytoplasmic extracts prepared from the brainstem of P10 transgenic $(\mathrm{Tg})$ or nontransgenic $(\mathrm{N}-\mathrm{Tg})$ mice were immunoprecipitated using anti-Flag $\mathrm{M} 2$ beads. Real-time RT-PCR quantification of MBP mRNA and PLP mRNA coimmunoprecipitated with Flag-QKI-6 (IP) was normalized to that of the corresponding mRNAs in the total input extracts (Inp) and graphically displayed. SE for each group is indicated $(n=4) .{ }^{*} p<0.05$ by standard $t$ test. The inset shows a representative image of the MBP and PLP mRNA in the input extract and immunoprecipitated QKI-6 complex by semiquantitative RT-PCR using ${ }^{32} \mathrm{P}$-labeled primers.

\section{Discussion}

In this study, we demonstrate for the first time that the QKI-6 isoform alone is sufficient to rescue the hypomyelination phenotype caused by the $\mathrm{qk}^{\mathrm{v}}$ mutation with no change in expression of the other QKI isoforms, suggesting that QKI-6 is the predominant isoform controlling CNS myelinogenesis. In addition, the fact that Flag-QKI-6 preferentially binds the MBP mRNA and rescues MBP expression from very early stages of myelin development suggests that MBP is a preferential target by which QKI regulates CNS myelinogenesis.

The $\mathrm{qk}^{\mathrm{v}}$ mutation affects three known genes, deleting the $3^{\prime}$ portion of the parkin gene (Lockhart et al., 2004; Lorenzetti et al., 2004a; Dapper and Justice, 2005), the entire parkin coregulated gene (PACRG) (Lockhart et al., 2004; Lorenzetti et al., 2004b), and a $5^{\prime}$ regulatory element of $q k I$ specifically required for QKI expression in myelinating cells (Ebersole et al., 1996). There has been a long debate in the literature regarding which of these affected genes is responsible for the $\mathrm{qk}^{\mathrm{v}}$ hypomyelination phenotype (i.e., functionally required for CNS myelination). Although genetic complementation analysis indicated that parkin and PACRG could not rescue the $\mathrm{qk}^{\mathrm{v}}$ hypomyelination phenotype (Cox et al., 1999), no direct evidence could be used to argue that diminished QKI expression was responsible for the failure of CNS myelinogenesis. We show here that expression of the QKI-6 isoform in the oligodendrocyte lineage (Fig. 2) rescues the dysmyelination phenotype of the $\mathrm{qk}^{\mathrm{v}}$ mutant (Figs. 4, 5), demonstrating for the first time that QKI deficiency is indeed the underlying mechanism for $\mathrm{qk}^{\mathrm{v}}$ hypomyelination.

It is important to note that QKI isoforms display differential patterns of temporal expression and subcellular localization. Thus, they are postulated to exert distinct influences on myelination (Hardy, 1998; Cox et al., 1999). The nuclear isoform QKI-5 causes nuclear retention of the MBP mRNA, thereby inhibiting MBP production (Larocque et al., 2002). This negative influence of QKI-5 on myelinogenesis presumably declines during neonatal development because of the reduced QKI-5 expression (Hardy et al., 1996; Kondo et al., 1999). In contrast, the cytoplasmic isoforms QKI-6 and -7 are upregulated during myelinogenesis and are severely reduced in $\mathrm{qk}^{\mathrm{v}}$ oligodendrocytes (Hardy et al., 1996) (Fig. 1). Hence QKI-6 and -7 are postulated to be positive factors for myelination. However, QKI-7 can also act as a potent apoptotic inducer (Pilotte et al., 2001), suggesting a bidirectional influence by QKI-7 on oligodendrocyte and myelin development. Because restoring QKI-6 expression alone rescues the defects in myelinogenesis in the $\mathrm{qk}^{\mathrm{v}}$ mutant, QKI-6 appears to be the isoform necessary and sufficient for CNS myelinogenesis. Although the expression and the hetero-oligomeric interactions between QKI isoforms (Wu et al., 1999; Pilotte et al., 2001) may function to more precisely control oligodendrocyte development, QKI-5 and QKI-7 are apparently nonessential for CNS myelinogenesis during neonatal development.

Multiple myelin structural gene mRNAs are severely reduced in the $\mathrm{qk}^{\mathrm{v}}$ mutant, including the MBP mRNA and the PLP mRNA (Roth et al., 1985; Sorg et al., 1986, 1987; Li et al., 2000). Posttranscriptional destabilization is the predicted mechanism that underlies the reduction of these mRNAs, because transcription of these genes is not affected (Li et al., 2000). Noticeably, not all myelin structural gene mRNAs are equally affected by QKI deficiency. The mRNA encoding the CNPase $\left(2^{\prime}, 3^{\prime}\right.$-cyclic nucleotide $3^{\prime}$-phosphodiesterase) is only slightly reduced (Zhang and Feng, 2001), and the mRNA of Olig1, an essential gene for CNS myelinogenesis (Arnett et al., 2004; Burton, 2005; Xin et al., 2005), is not affected (data not shown). Despite the fact that QKI deficiency causes comparable reduction of both the MBP and the PLP mRNAs, the QKI-6 transgene restores MBP expression but not PLP expression in neonates (Figs. 5-7). Expression of the PLP mRNA is restored only when Flag-QKI-6 level reaches a peak at P20, at which point there is more than fourfold more QKI-6 than is needed to maintain normal myelination in the $\mathrm{qk} / \mathrm{wt}$ controls (Fig. 3D). These results suggest that MBP is a preferential target for QKI.

Apparently, the intrinsic ability for these mRNAs to bind QKI is an underlying mechanism for the selective influence of QKI on myelin structural gene expression. Although both the MBP mRNA and the PLP mRNA harbor several consensus QREs (QKI responsible elements) identified by SELEX (Larocque et al., 2002; Galarneau and Richard, 2005; Aberg et al., 2006), MBP mRNA 
binds QKI more strongly than the PLP mRNA in vitro and in vivo (Fig. 8), which provides an explanation for the selective rescue of MBP expression by the QKI transgene during early myelin development (Fig. 7A). The delayed rescue of PLP expression by the QKI transgene (Fig. 7C,D) is most likely attributable to the relatively lower QKI-binding activity by the PLP mRNA (Fig. 8). It is worth mentioning that QKI can be phosphorylated by the SrcPTKs, which modulates the RNA-binding activity of QKI (Zhang et al., 2003). Hence, QKI has been postulated as a pivotal factor that links developmental signals to mRNA homeostasis (Vernet and Artzt, 1997). Consistent with this view, immunoprecipitated Flag-QKI-6 from the transgenic mice contains phosphotyrosine (data not shown). Whether and how tyrosine phosphorylation of QKI is involved in rescuing the $\mathrm{qk}^{\mathrm{v}}$ hypomyelination is an intriguing question to be answered by future studies.

In addition to the role in promoting myelin synthesis via enhancing the production of myelin structural proteins, QKI has also been reported to increase expression of the cyclin-dependent kinase inhibitor p27Kip1, a key factor that controls the transition of oligodendroglia progenitors from proliferation to differentiation (Durand et al., 1997; Casaccia-Bonnefil et al., 1999; Larocque et al., 2005). Indeed, forced expression of QKI-6 and -7 can enhance $\mathrm{p} 27 \mathrm{Kip} 1$ expression by stabilization of the p27Kip1 mRNA and promote oligodendrocyte differentiation (Larocque et al., 2005). In addition, our recent studies identified microtubule associated protein $1 \mathrm{~B}$ mRNA, a key protein regulating oligodendroglia processes extension (Vouyiouklis and Brophy, 1993), as a target of QKI (Zhao et al., 2006). Whether QKI deficiency indeed attenuates oligodendrocyte differentiation in the $\mathrm{qk}^{\mathrm{v}}$ mutant brain, and furthermore whether the QKI-6 transgene may promote oligodendrocyte differentiation before myelination, are important questions to be addressed by future studies. Although our results clearly indicate that MBP mRNA is a preferential target of QKI during myelination, the full range of mRNA ligands for QKI at various stages of oligodendroglia differentiation and myelinogenesis still remain unidentified. Our QKI-6 transgenic mice offer a unique tool for identifying in vivo oligodendroglia-specific mRNA targets of QKI. Studies on these mice should provide important insights regarding fundamental mechanisms that govern normal myelin development as well as myelin disorders caused by QKI dysregulation, such as schizophrenia (Aberg et al., 2006; McInnes and Lauriat, 2006).

\section{References}

Aberg K, Saetre P, Jareborg N, Jazin E (2006) Human QKI, a potential regulator of mRNA expression of human oligodendrocyte-related genes involved in schizophrenia. Proc Natl Acad Sci USA 103:7482-7487.

Arnett HA, Fancy SP, Alberta JA, Zhao C, Plant SR, Kaing S, Raine CS, Rowitch DH, Franklin RJ, Stiles CD (2004) bHLH transcription factor Olig1 is required to repair demyelinated lesions in the CNS. Science 306:2111-2115.

Burton A (2005) Olig1 needed for remyelination. Lancet Neurol 4:80.

Campagnoni AT, Macklin WB (1988) Cellular and molecular aspects of myelin protein gene expression. Mol Neurobiol 2:41-89.

Campagnoni AT, Sorg B, Roth HJ, Kronquist K, Newman SL, Kitamura K, Campagnoni C, Crandall B (1987) Expression of myelin protein genes in the developing brain. J Physiol (Paris) 82:229-238.

Casaccia-Bonnefil P, Hardy RJ, Teng KK, Levine JM, Koff A, Chao MV (1999) Loss of p27Kip1 function results in increased proliferative capacity of oligodendrocyte progenitors but unaltered timing of differentiation. Development 126:4027-4037.

Cox RD, Hugill A, Shedlovsky A, Noveroske JK, Best S, Justice MJ, Lehrach H, Dove WF (1999) Contrasting effects of ENU induced embryonic lethal mutations of the quaking gene. Genomics 57:333-341.

Dapper JD, Justice MJ (2005) Defining the breakpoints of the quaking(vi- able) mouse mutation reveals a duplication from a Parkin intron. Mov Disord 20:1369-1374.

Durand B, Gao FB, Raff M (1997) Accumulation of the cyclin-dependent kinase inhibitor $\mathrm{p} 27 / \mathrm{Kip} 1$ and the timing of oligodendrocyte differentiation. ЕMBO J 16:306-317.

Ebersole T, Rho O, Artzt K (1992) The proximal end of mouse chromosome 17: new molecular markers identify a deletion associated with quakingviable. Genetics 131:183-190.

Ebersole TA, Chen Q, Justice MJ, Artzt K (1996) The quaking gene product necessary in embryogenesis and myelination combines features of RNA binding and signal transduction proteins. Nat Genet 12:260-265.

Fuss B, Mallon B, Phan T, Ohlemeyer C, Kirchhoff F, Nishiyama A, Macklin WB (2000) Purification and analysis of in vivo-differentiated oligodendrocytes expressing the green fluorescent protein. Dev Biol 218:259-274.

Galarneau A, Richard S (2005) Target RNA motif and target mRNAs of the Quaking STAR protein. Nat Struct Mol Biol 12:691-698.

Hardy RJ (1998) Molecular defects in the dysmyelinating mutant quaking. J Neurosci Res 51:417-422.

Hardy RJ, Loushin CL, Friedrich Jr VL, Chen Q, Ebersole TA, Lazzarini RA, Artzt K (1996) Neural cell type-specific expression of QKI proteins is altered in quakingviable mutant mice. J Neurosci 16:7941-7949.

Hogan EL, Greenfield S (1984) Animal model of genetic disorders of myelin. New York: Plenum.

Jacque C, Delassalle A, Raoul M, Baumann N (1983) Myelin basic protein deposition in the optic and sciatic nerves of dysmyelinating mutants quaking, jimpy, Trembler, mld, and shiverer during development. J Neurochem 41:1335-1340.

Kondo T, Furuta T, Mitsunaga K, Ebersole TA, Shichiri M, Wu J, Artzt K, Yamamura K, Abe K (1999) Genomic organization and expression analysis of the mouse qkI locus. Mamm Genome 10:662-669.

Larocque D, Pilotte J, Chen T, Cloutier F, Massie B, Pedraza L, Couture R, Lasko P, Almazan G, Richard S (2002) Nuclear retention of MBP mRNAs in the quaking viable mice. Neuron 36:815-829.

Larocque D, Galarneau A, Liu HN, Scott M, Almazan G, Richard S (2005) Protection of p27(Kip1) mRNA by quaking RNA binding proteins promotes oligodendrocyte differentiation. Nat Neurosci 8:27-33.

Li Z, Zhang Y, Li D, Feng Y (2000) Destabilization and mislocalization of myelin basic protein mRNAs in quaking dysmyelination lacking the QKI RNA-binding proteins. J Neurosci 20:4944-4953.

Lockhart PJ, O'Farrell CA, Farrer MJ (2004) It's a double knock-out! The quaking mouse is a spontaneous deletion of parkin and parkin coregulated gene (PACRG). Mov Disord 19:101-104.

Lorenzetti D, Antalffy B, Vogel H, Noveroske J, Armstrong D, Justice M (2004a) The neurological mutant quaking(viable) is Parkin deficient. Mamm Genome 15:210-217.

Lorenzetti D, Bishop CE, Justice MJ (2004b) Deletion of the Parkin coregulated gene causes male sterility in the quaking(viable) mouse mutant. Proc Natl Acad Sci USA 101:8402-8407.

Lu Z, Zhang Y, Ku L, Wang H, Ahmadian A, Feng Y (2003) The quakingviable mutation affects qkI mRNA expression specifically in myelin-producing cells of the nervous system. Nucleic Acids Res 31:4616-4624.

Mallon BS, Shick HE, Kidd GJ, Macklin WB (2002) Proteolipid promoter activity distinguishes two populations of NG2-positive cells throughout neonatal cortical development. J Neurosci 22:876-885.

McInnes LA, Lauriat TL (2006) RNA metabolism and dysmyelination in schizophrenia. Neurosci Biobehav Rev 30:551-561.

Pilotte J, Larocque D, Richard S (2001) Nuclear translocation controlled by alternatively spliced isoforms inactivates the QUAKING apoptotic inducer. Genes Dev 15:845-858.

Privat A, Jacque C, Bourre JM, Dupouey P, Baumann N (1979) Absence of the major dense line in myelin of the mutant mouse "shiverer." Neurosci Lett 12:107-112.

Readhead C, Popko B, Takahashi N, Shine HD, Saavedra RA, Sidman RL, Hood L (1987) Expression of a myelin basic protein gene in transgenic shiverer mice: correction of the dysmyelinating phenotype. Cell 48:703-712.

Roth HJ, Hunkeler MJ, Campagnoni AT (1985) Expression of myelin basic protein genes in several dysmyelinating mouse mutants during early postnatal brain development. J Neurochem 45:572-580.

Sidman RL, Dickie MM, Appel SH (1964) Mutant mice (Quaking and 
Jimpy) with deficient myelination in the central nervous system. Science 144:309-311.

Singh H, Spritz N, Geyer B (1971) Studies of brain myelin in the "quaking mouse." J Lipid Res 12:473-481.

Sorg BA, Smith MM, Campagnoni AT (1987) Developmental expression of the myelin proteolipid protein and basic protein mRNAs in normal and dysmyelinating mutant mice. J Neurochem 49:1146-1154.

Sorg BJ, Agrawal D, Agrawal HC, Campagnoni AT (1986) Expression of myelin proteolipid protein and basic protein in normal and dysmyelinating mutant mice. J Neurochem 46:379-387.

Vernet C, Artzt K (1997) STAR, a gene family involved in signal transduction and activation of RNA. Trends Genet 13:479-484.

Vouyiouklis DA, Brophy PJ (1993) Microtubule-associated protein MAP1B expression precedes the morphological differentiation of oligodendrocytes. J Neurosci Res 35:257-267.
Wu J, Zhou L, Tonissen K, Tee R, Artzt K (1999) The quaking I-5 protein (QKI-5) has a novel nuclear localization signal and shuttles between the nucleus and the cytoplasm. J Biol Chem 274:29202-29210.

Xin M, Yue T, Ma Z, Wu FF, Gow A, Lu QR (2005) Myelinogenesis and axonal recognition by oligodendrocytes in brain are uncoupled in Olig1null mice. J Neurosci 25:1354-1365.

Zhang Y, Feng Y (2001) Distinct molecular mechanisms lead to diminished myelin basic protein and $2^{\prime}, 3^{\prime}$-cyclic nucleotide $3^{\prime}$-phosphodiesterase in qk(v) dysmyelination. J Neurochem 77:165-172.

Zhang Y, Lu Z, Ku L, Chen Y, Wang H, Feng Y (2003) Tyrosine phosphorylation of QKI mediates developmental signals to regulate mRNA metabolism. EMBO J 22:1801-1810.

Zhao L, Ku L, Chen Y, Xia M, Lopresti P, Feng Y (2006) QKI binds MAP1B mRNA and enhances MAP1B expression during oligodendrocyte development. Mol Biol Cell 17:4179-4186. 